\title{
Improving the coordination in the humanitarian supply chain: exploring the role of options contract
}

\author{
Lijo John ${ }^{1} \cdot$ Anand Gurumurthy ${ }^{2} \oplus \cdot$ Arqum Mateen $^{2}$. \\ Gopalakrishnan Narayanamurthy ${ }^{3}$ (D)
}

Published online: 15 September 2020

(c) The Author(s) 2020

\begin{abstract}
The uncertainty associated with the location, severity and timing of disaster makes it difficult for the humanitarian organization (HO) to predict demand for the aid material and thereby making the relief material procurement even more challenging. This research explores whether options contract can be used as a mechanism to aid the $\mathrm{HO}$ in making procurement of relief material less challenging by addressing two main issues: inventory risk for buyers and over-production risk for suppliers. Furthermore, a contracting mechanism is designed to achieve coordination between the $\mathrm{HO}$ and aid material suppliers in the humanitarian supply chain through optimal pricing. The options contract is modelled as a stylized version of the newsvendor problem that allows the HO to adjust their order quantity after placing the initial order at the beginning of the planning horizon. This flexibility helps to mitigate the risk of both overstocking and understocking for the $\mathrm{HO}$ as well as the risk of overproduction for the supplier. Our results indicate that the optimal values for decision parameters are not "point estimates" but a range of prices, which can facilitate negotiation between the two parties for appropriate selection of contract parameters under an options contract. The results imply that options contract can aid in the decentralized approach of fixing the prices between the $\mathrm{HO}$ and the supplier, which in turn would help in achieving systemic coordination.
\end{abstract}

Keywords Humanitarian supply chain · Options contracts · Newsvendor problem · Coordination · Procurement

\section{Introduction}

The procurement of aid material is a critical function in the humanitarian supply chain (HSC), and the procurement managers at the humanitarian organization (HO) often try to balance between cost and responsiveness in their planning. Moreover, the HO has to respond to different types of disasters, which require a variety of relief items ranging from simple supplies (e.g. food) to complex equipment (e.g. radios, batteries, machinery, etc.) (Lamenza et al. 2019). Thus, HO needs different kinds of products with different characteristics, demand

Extended author information available on the last page of the article 
variability and procurement sources. The challenges in meeting the demand of aid material in HSC is different from the commercial supply chain (CSC). The timing, location, severity of the disaster, institutional stability, and special requirements based on the geography and/or culture of the affected area have to be considered while offering solutions (Wamba 2020) and thereby adds to the complexity of the procurement process in HSC (Balcik 2014). Also, in the interest of the responsiveness, the $\mathrm{HO}$ seldom resort to time-consuming bidding based procurement during the post-disaster response stage (Ertem et al. 2010). Hence, to streamline the procurement process, and to ensure cost-effective and quick delivery of the aid material, $\mathrm{HO}$ gets into contractual agreements with suppliers during the preparedness stage itself. The pre-disaster contractual agreements or long-term agreements (Balcik 2014) with the suppliers are aimed at having procurement flexibility to mitigate the uncertainty in demand.

Contracts have been widely used in the CSC to achieve channel coordination. It also ensures that the risk is shared suitably between the contracting parties while bringing the overall profit of the decentralized supply chain closer to a centralized supply chain. Options contract have been found to offer multiple benefits in a CSC setting, such as:

- Providing the buyer with the flexibility to respond to demand uncertainty and to achieve coordination (Barnes-Schuster et al. 2002),

- Introducing flexibility in the retailer-supplier commitment (Ben-Tal et al. 2005),

- Mitigating the risk associated with future consumer demand (Li et al. 2016),

- Addressing the procurement cost fluctuation (Xiao et al. 2015), and

- Designing firm-level optimal trading policy (Xu et al. 2020), among others.

Similarly, the use of contracts in HSC is also gaining traction. One of the main objectives of such contracts in HSC is to stimulate the much-needed flexibility in the procurement process. Previous studies on the type of contractual agreements with the suppliers (e.g. Wang et al. 2015; Liang et al. 2012, Turkeš et al. 2019) have compared the utility of each contract over the other and their relevance in HSC. For instance, Liang et al. (2012) compared the options contract with a traditional price contract and the buy-back contract and identified that pure options contract works better than both. However, these studies do not explore the use of contracts in the presence of multiple sources of procurement for the aid material. In practice, $\mathrm{HO}$ would purchase a part of the forecasted demand at the beginning of the planning horizon and employ multiple mechanisms and agreements to procure the remaining portion of the total forecasted demand depending on the actual demand during the planning horizon. The role of the options contract under such a context is not explored adequately in the literature.

Used initially in financial derivatives (Black and Scholes 1973), the options contracts have gained traction in the domain of SCM due to their ability to create flexibility in procurement. On the one hand, the options contract offers the buyer the flexibility to respond to the stochastic demand by purchasing the right (but not obligation) to increase or cancel the order at a specified price at a later point in time. On the other hand, the seller gets to charge a premium (share demand risk) and an early commitment to planning the capacity (Eriksson 2019). This nature of HSC makes it quite attractive for the options contract to be used in the HSC as a procurement mechanism, where $\mathrm{HO}$ would exercise the option for further procurement upon realizing the demand.

A similar mechanism is followed by World Vision (India) where about 5-10\% of the forecasted requirement is procured during the beginning of the planning horizon. Another $15 \%$ of the requirements are being converted to optional purchase under a predetermined price set under the options contract (K. Shah, personal communication). Furthermore, the options contract gives the $\mathrm{HO}$, adequate flexibility to order the required quantity of the aid material after the actual field level information is made available post-disaster (Liang et al. 
2012). However, it is worthwhile to note that in practice, HOs use other mechanisms as well to plan for the procurement of the forecasted amount of aid material. These include up-front purchases, the trade agreement with suppliers, formal and informal agreement with other HOs, private sector donations, national stocks held by the governments and purchase through spot markets. While a significant part of the pre-assumed demand (about 60\%) is fulfilled through cooperated suppliers, rest is often left to be tackled during the actual realisation of the demand (Hu et al. 2019). Hence, the HO would prefer to achieve an optimal trade-off between the multiple procurement mechanisms. Therefore, in this study, we examine the use of options contract between the $\mathrm{HO}$ and the supplier in the presence of other procurement mechanisms as well. Through this exploration, we formalize the use of the options contract model for the procurement of aid material and address the following research questions (RQs):

RQ1 How does the adoption of options contract in HSC help achieve coordination in the presence of a portfolio approach followed by a HO for procurement?

RQ2 What are the conditions under which the options contract can achieve systemic coordination between $\mathrm{HO}$ and suppliers?

Our results indicate that the options contract would help in a decentralized price-fixing between $\mathrm{HO}$ and supplier. This, in turn, redistributes the risk for both the parties and thereby enabling the HSC to achieve optimality. It allows both stakeholders to identify optimal values individually while still achieving systemic optimality. Furthermore, optimal values for the decision variables of $\mathrm{HO}$ can be obtained over a range of prices with a corresponding split between initial fixed order and optional purchase allowing the HO to decide on the optimal procurement policy. Depending on the order split between the initial order and the enforcement of options contract by the HO, the supplier can also choose an optimal combination of the prices for the option price and exercise price within a given range.

The rest of the paper is organized as follows. Section 2 reviews the pertinent literature, and Sect. 3 explains the model formulation and optimality conditions. Section 4 presents an illustrative example, while Sect. 5 discusses the results obtained, and Sect. 6 concludes the research.

\section{Literature review}

We review the literature on two streams that are directly relevant to this study: coordination in HSC and options contract in the supply chain in general. Following the review, we present the initial insights obtained by interacting with the procurement manager of a leading global aid agency on the portfolio approach for aid management and then finally summarize the section with research gaps.

\subsection{Coordination in HSC}

The coordination in HSC is unique in comparison to the CSC owing to a multitude of factors such as number and diversity of actors (van wassenhove 2006), donor expectation and funding structure in HSC (Stephenson and Schnitzer 2006), competition for funding, the impact of media, social media and disruptive technologies on relief activities (Seaman 1999; 3. Al Qundus et al. 2020; Loynes et al. 2020; Nagendra, et al. 2020), unpredictability associated with operational environment (Day et al. 2012), resource scarcity and oversupply (Russell 
2005), cost of coordination (Stephenson 2005) and decentralized behaviour of individuals (Muggy and Stamm 2020). HSC needs to be both agile and flexible to meet the dynamic needs through inter- and intra-organizational coordination (Jahre and Fabbe-Costes 2015).

Balcik et al. (2010) identified that coordination in HSC depends on "relationships and interactions among different actors operating within the relief environment" (p. 23). Wagner and Thakur-Weigold (2018) argued that the HO needs to develop relationships horizontally, vertically and cross-functionally in HSC. A similar distinction was made by Makepeace et al. (2017), where they identify these relationships as external (horizontal and vertical) and internal (cross-functional). The horizontal relationships would be the collaboration with other HOs and support providers. This type of relationships can be observed in the humanitarian clusters (Jensen and Hertz 2016). Vertical relationships are the ones formed with organizations which are working together with both upstream and downstream to share responsibilities, information and resources to feed the pipeline into humanitarian operations. Finally, crossfunctional relationships in an HSC refers to the internal relationship or partnership within an organization (i.e., HO) or the community where the humanitarian operations are undertaken (Wagner and Thakur-Weigold 2018). Thus, it is evident that the studies on coordination in HSC span a wider range of topics.

Often the term coordination and collaboration has been used interchangeably in HSC literature. Moshtari (2016) identified that inter-organizational collaboration refers to a process where two or more independent organizations share resources (e.g., information, expertise, and infrastructure) or work closely to design and implement their operations. Such inter-organizational collaboration includes two facets - coordination and cooperation. Interorganizational coordination refers to efforts in aligning organizations' tasks or actions to achieve cooperatively specified goals. On the other hand, inter-organizational cooperation refers to setting collaboration goals (e.g., enhanced legitimacy and lower operations costs) and negotiating and deciding on the amount of resources (e.g. information, manpower, expertise, etc.) (Gulati et al. 2012). Thus it can be understood that "a cooperation perspective" deals with agreements on frameworks and policies between the various stakeholders. In contrast "a coordination perspective" focuses on mechanisms to achieve the same (Moshtari 2016). For instance, Jahre and Fabbe-Costes (2015) identified that both informal and formal standards be leveraged to implement modularity in humanitarian operations. Here, while developing standards are a part of inter-organizational cooperation, modularity is a mechanism to achieve inter-organizational coordination (Jabbour et al. 2019).

Inter-organization cooperation studies within the domain of HSC include developing cooperation between actors, proposing swift trust developing and testing frameworks, identifying enablers and barriers, etc. (Behl and Dutta 2019). For instance, during the Haitian earthquake, impediments to information flow between the stakeholders (Altay and Labonte 2014) affected coordination. In another case, UN logistics clusters acted as a centralized agency to improve the civil-military cooperation for effective airflow management (Morales and Sandlin 2015). One of the main challenges in achieving operational coordination between parties arise from the slow information flow and delay in the efficient allocation of resources (Fawcett and Fawcett 2013). Heaslip et al. (2012) highlighted the importance of channelling information flow between secondary stakeholders (operational) and primary stakeholders (strategic) in civil-military coordination through a stakeholder management approach. Furthermore, greater involvement of local population improves information flow and efficiency by decentralizing the decision making during relief activities (Sheppard et al. 2013).

Another critical factor for getting various stakeholders to cooperate is to have high levels of commitment (Kabra and Ramesh 2015) through rapid trust-building between the HOs converging at the location of disaster (Moshtari 2016). Swift trust is a form of trust occurring 
in temporary teams, particularly under time pressure or when achieving project goals is of utmost importance as observed in the post-disaster scenario (Dubey et al. 2019a). Big data coupled with analytical capability (Dubey et al. 2019b) and information sharing (Tatham and Kovács 2010) can be critical in enhancing swift trust formation between the HOs. This also positively affects HSC visibility and improves cooperation among the stakeholders (Dubey et al. 2018).

As discussed earlier, inter-organizational coordination studies focus on mechanisms used by HOs to achieve coordination. These include classical supply chain problems such as inventory management (Lodree 2011; Bemley et al. 2013), facility location (Yi and Özdamar 2007; Edrissi et al. 2013), procurement (Ertem and Buyurgan 2011), etc. For instance, the inefficiencies in procurement operations in HSC due to lack of organized suppliers and partnerships affect multiple procurements within a single planning horizon under demand uncertainties (Ertem and Buyurgan 2011). Lodree (2011) studied the surge in demand for commodities during a storm and compared the reactive vs proactive decision making using a standardized EOQ model. In a similar context, Bemley et al. (2013) considered the prepositioning strategies of repair items for port recovery in advance as a response to a natural disaster through a two-stage model. Similarly, for a two-stage procurement model, Yao et al. (2018) identified that when the difference between the proactive cost and reactive cost is lower than the expected delay and shortage cost, the purchasers will store relief supplies in advance to ensure a quick response; otherwise, they would follow a reactive approach. HOs typically pre-position relief items in strategic locations. The optimum storage levels are affected by the amounts of pre-disaster contractual agreements and post-disaster procurements. In the postdisaster relief stage procurement, $\mathrm{HO}$ often uses pre-positioning aid inventory for improving the location coverage and post-disaster responsiveness especially in case of the sudden onset natural disasters such as earthquakes (Edrissi et al. 2013). Torabi et al. (2018) used a quantity flexibility contract for coordinating with suppliers to enable the $\mathrm{HO}$ to reduce the amount of pre-positioned inventory while improving the post-disaster responsiveness. Nikkhoo et al. (2018) explored the use of quantity flexibility contract allowing both upward and downward adjustments in the aid material procurement to address the demand uncertainty while reducing the shortage cost and wastage due to overestimation. On the other hand, Chen et al. (2017) achieved the flexibility in procurement and optimal relief material pre-positioning using a generalized two-stage model in which materials are delivered in the first stage, and all backlogged demands are satisfied in the second stage after the disaster. While procurement for pre-positioning of relief material improves responsiveness, the choice of their location is also essential. Yi and Özdamar (2007) showed that the selection of sites for maximum coverage of medical needs in the affected areas is critical for logistic coordination. They employed a flexible, dynamic coordination model with multi-period decision making regarding vehicle routing and reallocation of capacities. Loree and Aros-Vera (2018) used mixed-integer nonlinear programming to identify optimal locations for point of distribution to reach survivors and allocate inventory for local delivery in post-disaster relief activities.

As observed from the preceding discussions, both inter-organizational cooperation and coordination studies in HSC studies have explored various facets of challenges in achieving collaboration in HSC. One of the major focus of coordination in HSC is the procurement of aid material. Recent estimates indicate that about $65 \%$ of the total cost of humanitarian activities can be traced back to procurement (Lamenza et al. 2019). Hence, in this study, we focus on the use of options contract, a mechanism used by the HO for improving the flexibility in procurement along with other procurement practices. 


\subsection{Options contracts in the supply chain}

The use of contracts for improving coordination in the CSC is well understood. The contracts help in enhancing the total SC profit, reduce overstock/understock costs and share the risks among the supply chain partners (Tsay 1999). Capacity reservation contracts have been used to achieve managerial flexibility and economic efficiency under uncertain demand (Eriksson 2019). The options contract, which is a combination of buy-back and quantity flexibility contracts allows flexible procurement under uncertainty (Cachon 2003). Eppen and Iyer (1997) studied the case of backup agreement, which was mainly an options contract with a two-stage model and identified that backup agreements can have a significant impact on the profit and committed order quantities of the supply chain members. Serel et al. (2001) considered the options contract as a capacity reservation contract where the buyer has the right to exercise any amount to buy within the reserved capacity and also explored the decision of when the buyer can also choose from the spot market.

Spinler and Huchzermeier (2006) extended the model to explore the purchasing decision for non-storable goods when the buyer has access to both options contract and spot-market purchase. Zhao et al. (2010) demonstrated that under unequal bargaining powers, options contract could achieve coordination when compared to the wholesale price contracts considering individual risk preferences and bargaining power of the supply chain members. Under a predetermined service requirement, Chen and Shen (2012) derived the optimal ordering and production policy using the options and wholesale price contracts between the manufacturer and the retailer. Chen et al. (2014) showed that the options contract could create flexibility to coordinate the supply chain bilaterally in a setting where the retailer is assumed to be loss averse, and the supplier is risk-neutral. Wang and Chen (2015) applied the options contract in a newsvendor setting (perishable products) to study the problem of joint ordering and pricing. Nosoohi and Nookabadi (2016) provided a numerical analysis that gives insights on the value of options contract for different parameter settings. Shi and Feng (2016) examined the usefulness and risks of supply contracts from a supplier's perspective and used real options to investigate the supplier's acceptance towards a supply contract with variable cost and supply-demand uncertainties.

Contracts as a coordination mechanism have received only limited treatment in the context of HSC. However, a few noteworthy studies demonstrating HSC coordination through contracts are to be mentioned here. For instance, Shamsi et al. (2018) developed an options contract model to proactively procure the required vaccine from the suppliers using a Susceptibility-Infection-Recover (SIR) epidemic model. Fathalikhani et al. $(2018,2020)$ used the Stackelberg games, where the humanitarian NGO's were considered as leaders and donors were represented as followers. Aflaki and Pedraza-Martinez (2016) used the Stackelberg game with the HOs as leaders to model the trade-off between funding strategies and operational performance in the humanitarian operations. Under the procurement of aid materials, Liang et al. (2012) explored the options contract mechanism in a two-step option pricing model with a binomial lattice to estimate the optimal option prices. Further, they identified the impact of the ratio of stocks kept by buyer and seller, probability of disaster and proportion of executed options by the buyer on risk reduction and improving the profits for both stakeholders. Inderfurth and Clemens (2014) argued that the HSC could achieve coordination even under the wholesale price contracts if the supplier has an emergency procurement source. Toyasaki et al. (2017) studied the role of joint procurement under an umbrella organization using a newsvendor model under non-cooperative game theory to understand the role of incentives in achieving overall coordination under umbrella organizations. Wang et al. (2019) argued that while framework agreements between the $\mathrm{HO}$ and suppliers exist, in practice, it 
does little to motivate suppliers to improve the effectiveness further. Hence, they suggested an additional bonus contract to incentivize the suppliers to meet the contractual obligations. Wang et al. (2015) demonstrated that pre-purchasing using the options contract outperforms the pre-purchase with buy-back contracts and instantaneous purchase with returns contract. Liu et al. (2019) explored the use of options contract to plan the procurement of relief supplies to determine the decision of what quantity of relief supplies should be stockpiled by the government, and the amount of inventory to be pre-positioned at each supplier. In a similar context, Hu et al. (2019) proposed a procurement model based on a put option contract between the government and the supplier.

To summarize the preceding discussion, the $\mathrm{HO}$ use a variety of mechanism to tackle the demand uncertainty affecting the procurement of aid material and to improve the effectiveness of the humanitarian operations. While options contract is a useful mechanism to address this demand uncertainty, it is often used along with other procurement mechanisms. Hence, to gain further insights into these mechanisms, we interacted with practitioners to understand the process of aid material procurement in HO. In Sect. 2.3, we summarize the salient points of the interaction we had with the humanitarian logisticians. Subsequently, we discuss how this research draws its motivation both from the practice as well as from the previous studies to address those aspects that have been overlooked so far.

\subsection{Portfolio approach for aid management}

Previous studies (Lamenza et al. 2019; Balcik and Ak, 2014; Ertem et al. 2010) have explored various facets of procurement in HSC. Scholten et al. (2018) interacted with procurement managers of global HO to study how supply chain flexibility can be employed to address the challenges in the demand variability in the European refugee context. Similarly, in this case, we interacted with the procurement manager of a leading global aid agency to understand the procurement process of a $\mathrm{HO}$.

The annual planning for the procurement of aid material (such as ready-to-eat meals, medical kits (including dressing materials, medicines, surgical sutures), supplementary food items, therapeutic food, etc.) begins with the forecast of the number of major and minor disasters that might occur during the forthcoming financial year. The forecast for the aid materials is based on the following:

- The actual consumption of the aid material in the past;

- Emergency preparation; and

- A safety level.

Emergency preparation is also a type of safety stock to cope with emergencies, and it is consumption invariant (Van der Laan et al. 2016). Owing to the budgetary constrained and high levels of uncertainty, stocking aid material for the entire forecasted requirement is challenging for the HO (Pedraza Martinez et al. 2011). Hence, the HO would keep only a little portion of the aid material as an internal stock in their warehouses while planning for the procurement of rest of the forecasted demand through multiple mechanisms (Balcik and Ak, 2014).

One such mechanism is to get into long term agreements with major private companies such as retail giants like Carrefour and Walmart and use their stocks to meet demand. These relationships are not contractual but often based on long term relationships and are usually handled by the corporate social responsibility teams of such private organisations. As noted by the United Nations International Children's Emergency Fund (UNICEF) in their annual supply report, Procter and Gamble $(\mathrm{P} \& \mathrm{G})$ and Unilever are registered corporate partners 
with UNICEF. Since 2006, through its "1 Pack = 1 Vaccine" campaign, P\&G has supported UNICEF's Maternal and Neonatal Tetanus Elimination Program, a global campaign to protect the lives of mothers and babies in developing and under-developed countries (UNICEF 2018).

Another frequent method employed by the $\mathrm{HO}$ is to borrow/source a portion of total demand from other HOs when the initial pre-positioned stock is either used up or stocked too far from the disaster site. When acting as the "service providers", UN agencies or international HOs can provide services such as warehousing, distribution, inventory management, fleet services and management, etc. along with joint procurement and sharing aid material (Pedraza-Martinez, et al. 2011). To facilitate this exchange of aid material between the HOs, agencies such as UN Joint Logistics Centre (UNJLC), Humanitarian Procurement Centre (HPC), etc. procure large quantities of aid material as "white material". These white material (i.e. untagged aid material) are pre-positioned at various locations across the globe (see Toyasaki et al. 2017). The member HO can use these materials upon requirement. One of the challenges in using the "white goods" is the availability of the excess stock when required by the $\mathrm{HO}$ and the significant transportation cost associated with the moving these materials from the pre-positioned warehouse to the site of the disaster.

The $\mathrm{HO}$ also resort to last-minute procurement from the local markets or other vendors. This depends on the location and the magnitude of the requirement. Even though this mechanism might be the costliest, it is also the most responsive. Therefore, the HOs resort to local procurement as they need to respond immediately in the initial week of the disaster (Wang et al. 2019; Balcik 2014).

To summarize, the HO resort to a portfolio approach to meet their total forecasted demand, including a combination of multiple procurement mechanisms through a nexus of both formal and informal contracts. Since a significant part of the procurement occurs after the disaster when there is more clarity regarding the demand, fixed and optional orders in the pre-disaster phase constitute only about $20 \%$ of the net forecasted demand. Furthermore, except for the spot market procurement, all other alternative mechanisms are generally non-contractual or informal and philanthropic. Hence, procurement decisions made in the pre-disaster phase by HOs are restricted to only internal stocking options. Finally, during the preparedness phase, the procurement decision primarily hinges on the prices for the quantity of aid material procured under fixed and options contract through a formal contract mechanism. However, in a post-disaster condition, getting a sufficient amount of the aid material becomes a pertinent issue. Furthermore, the impact, severity and the location of disaster cannot be predicted upfront. Thus, even though HOs have a portfolio of approaches to meet the demand, not all strategies can be planned for in the preparedness stage.

\subsection{Research Gap}

To conclude the discussion in preceding sections, a collaboration between the stakeholders in HSC is imperative for effective humanitarian operation. While cooperation focusses on the frameworks and policies to improve the collaboration, coordination focusses on the mechanisms to achieve the same. Use of contracts and agreements is one such mechanism used by the HOs. Contracts have received much attention in the literature as a mechanism to achieve coordination between the relevant stakeholders. Among the various types of contracts, options contract has attracted significant attention as a tool to gain flexibility while addressing the uncertainty in the procurement process. In HSC, previous studies such as Liang et al. (2012) focused on the pricing of the options contract while Wang et al. (2015) explored the choice between contracts that are best suited for "internal stocks" and "negotiated agreements". 
Toyasaki et al. (2017) investigated the conditions under which and mechanism to incentivize the HO to align their motivation with that of the joint procurement forum such as UN Humanitarian Response Depot. Liang et al. (2012) and Wang et al. (2015), utilized the single-period models and tried to find a feasible range and acceptable prices for both suppliers and the HOs. Our study is different from these studies. First, we develop a combined optimization model including both mechanisms, namely fixed and optional procurement, used by HO in the pre-disaster procurement rather than comparing these approaches. Since in practice, it is highly unlikely to use only one of the two methods, our study is closer to the actual practice. Second, we focus on proposing actionable strategies in HSC to help the decision-makers formalize the procurement process and identify the optimal prices by combining both the "internal stock" and the "negotiated agreements". We focus on decision making under the joint procurement option in pre-disaster procurement planning.

\section{The model}

Since HSC is a not-for-profit supply chain, ascertaining a monetary value for the services offered by the $\mathrm{HO}$ is challenging. While the cost of operations and aid material delivered is identifiable, it is not easy to assign a value perceived by the beneficiary for the aid material received. There are two views in HSC around the quantification of the value for the services offered by the HO. Firstly, the deprivation cost approach argues that the total cost of humanitarian operations, when seen strictly from a logistical point, fails to capture true nature of the cost of human (Holguín-Veras et al. 2013). The deprivation cost is the economic value of human suffering caused by the lack of access to aid or assistance. It is defined as a function of deprivation time and socio-economic characteristics of the individual (e.g. age, gender, physical condition, etc.). However, calculating deprivation costs bears similar problems as calculating the penalty costs for unmet demand since they are controversial as they put a price on human suffering and it is tough to quantify (Turkeš et al. 2019).

Nonetheless, the basic principle of the HSC is to satisfy the beneficiaries' needs whenever required. In general, HOs strive to do the best for their beneficiaries by helping them during both the emergency and the restoration of normalcy without any profit motive (Santarelli et al. 2015). McGinnis (2000) argued that a beneficiary associates a higher economic value to aid since it is often received in a dire situation. In some cases, non-availability of the aid material at the right time can make a difference in terms of life and death of a beneficiary. However, the total cost of providing aid material would include the cost of aid material, transportation cost to the affected areas, warehousing and other logistics cost, including overheads. In the case of CSC, the final selling price would reflect these costs along with the profit margin. Since HO is a not-for-profit organization, the concept of "selling" the aid material is inappropriate. Hence, the satisfaction value is used as a proxy for the selling price in the profit function and captures the value of aid received by the recipients (Wang and Chen 2015).

The aid procurement model is set as a single period newsvendor problem. The notations used to capture the scenario mentioned above in an HSC are summarized below.

$X$ demand for aid material serviced by the $\mathrm{HA}(\mathrm{X} \geq 0), f(\cdot)$ probability distribution function of the demand, $F(\cdot)$ cumulative probability density function of the demand, $S$ Satisfaction value, $P$ unit wholesale price of aid material, $P_{I}$ the unit retail price of the aid kit for spot purchase by HA, $V$ salvage price of the aid material, $c$ option price for every unit, $P_{o}$ the exercise price for each unit procured under the option contract, $w$ wholesale procurement price of raw material for supplier, $w_{I}$ wholesale procurement price of raw material for the 
supplier under the instantaneous purchase, $Q$ initial order by the HA, $q$ order under the options contract by the HA.

\subsection{Centralized and decentralized model for HSC}

We assume both $\mathrm{HO}$ and the aid supplier to be risk-neutral. In a centralized HSC, only a single entity acts as the decision-maker, and the focus is on optimizing the system as a whole. The profit function of the centralized decision-maker in the HSC is

$$
E\left(\pi_{C}\right)=S E(X)+V E \operatorname{Max}(Q-X, 0)-w Q-w_{I} E \operatorname{Max}(X-Q, 0)
$$

The first term in the profit function of the centralized system denotes the total satisfaction value of meeting the demand arising from the beneficiaries. The second term indicates the net salvage value for unused aid material. The third and fourth term denotes the cost of procuring the aid material from the supplier at the beginning of the planning horizon and instantaneous purchase from the spot market after the demand, respectively. If the expected total demand is $\mu$, then based on standard results, Eq. (1) can be re-written as:

$$
S \mu+V \int_{0}^{Q} F(X) d X-w Q-w_{I}\left(\mu-Q+\int_{0}^{Q} F(X) d X\right)
$$

The second-order derivative shows that the profit function is negative, indicating the concavity of the profit function. First-order conditions (3) can be used to arrive at the optimal ordering quality by the $\mathrm{HO}$ at the beginning of the planning horizon. The optimum ordering quantity for the integrated system is given by $Q_{C}^{*}=F^{-1}\left[\frac{w_{I}-w}{w_{I}-V}\right]$.

$$
\frac{d}{d Q} E\left(\pi_{C}\right)=-\left(w-w_{I}\right)-\left(w_{I}-V\right) F(Q)=0
$$

In the decentralized HSC, both the HO and the supplier do not coordinate while fixing the prices, and they try to maximize their individual gains. For a wholesale price-only contract between the $\mathrm{HO}$ and supplier, the profit function is similar to the centralized system. However, HO procures the aid material from the supplier at wholesale price $(P)$ and instantaneous prices $\left(P_{I}\right)$ before and after the disaster respectively. In that case, the profit function is rewritten as

$$
E\left(\pi_{D}\right)=S E(X)+V E \operatorname{Max}(Q-X, 0)-P Q-P_{I} E \operatorname{Max}(X-Q, 0)
$$

Following the similar reasoning as in the case of the centralized system, we get the optimal order quantity for $\mathrm{HO}$ under the decentralized system to be $Q_{D}^{*}=F^{-1}\left[\frac{P_{I}-P}{P_{I}-V}\right]$.

\subsection{Options contract}

We consider the aid material procurement process (as explained earlier) followed by the HO. The planning horizon begins with the forecast for the next period. Based on the estimates, the $\mathrm{HO}$ decides on the order to be placed with the suppliers. As discussed in the previous section, only a part of the estimated demand would be procured during the preparedness phase. HO places an order of quantity $Q$ at a price $P$ for each unit. Furthermore, HO also places additional order for $q$ units with the option price of $c$ per unit. Once the HO has placed their order, supplier starts the production based on specifications set by HA and deliver a part of the initial order to the HO's warehouse at the beginning of the planning horizon. 
Once the disaster strikes, the HO initiates their relief program by taking a quick stock of the situation to estimate the amount of aid material required. Subsequently, the HO would use the aid material from the internal stock. The HO would then decide on getting additional stock depending upon the extent of damage, and the duration of the relief operation. Subsequently, HO decides either exercise its option for an exercise price of $P_{o}$ in full or parts depending upon the requirement during the post-disaster relief scenario. This contract gives $\mathrm{HO}$ an option to buy $q$ units of aid material at an exercise price of $P_{o}$ if required, but not an obligation to do the same at a later point. However, the supplier is obligated to stock enough quantity of aid material to meet any demand from $\mathrm{HO}$, if and when they decide to exercise the option. If the demand for the aid material exceeds the initial order and optional order, then the HO would resort to purchasing the remaining part of the demand at the spot market price $P_{I}$. Finally, the supplier can dispose of the unpurchased stock relief materials after the options contract expires.

The option contract provides HO with the flexibility to procure extra quantities of the aid material at a predetermined price. HO gets the flexibility to order any quantity between $Q$ and $(Q+q)$ while the supplier is obliged to provide up to $(Q+q)$ when required. This flexibility relieves the $\mathrm{HO}$ from holding a massive amount of inventory, thereby reducing the inventory obsolescence and the holding cost. Similarly, it also minimises the dependence on the spot market. Similarly, the contract compensates the supplier by pricing the extra quantities bought under an option contract at a premium to offset the risk of holding the excess inventory. The following assumptions are made to avoid trivial solutions.

I. $\quad P_{I} \geq P$ : The spot purchase price for the aid material after the disaster will be higher than the initial wholesale procurement price at the beginning of the planning horizon.

II. $c+P_{o} \geq P$ : The total price for aid material bought under the option contract, including both the initial option price and subsequent exercise price should be more than the initial purchase. Without this condition, it would be cheaper to buy aid material using the options contract when compared to a regular purchase.

III. $P_{I} \geq c+P_{o}$ : HO will first resort to using the options before opting to purchase from the spot market. A violation of this assumption will make the spot purchase more attractive than exercising the options contract.

IV. $c \leq P-V$ : If the salvage price is high enough, then it would make more sense for the $\mathrm{HO}$ to purchase the entire forecasted quantity upfront and salvage those items later if they are unused.

V. $P_{o} \geq V$ : If the salvage value is higher than the exercise price of the optional quantity, the supplier will salvage themselves rather than keeping up the terms of the contract. In other words, the supplier will not have any incentive to service the excess demand of the HA.

VI. $c+P_{0}-w<P_{I}-w_{I}$ : If the marginal revenue obtained from the sale of aid material under options contract is less than the marginal revenue from the spot sale, then the supplier has no incentive to be in the options contract and would wait for the instant purchase after the disaster.

The options contract depends upon the parameters defined by $c, P_{o}, Q$, and $q$. We model the bargaining process between the $\mathrm{HO}$ and supplier as a Stackelberg game. The HO ask for the supplier for the option to procure the aid materials in parts based on the forecast. Supplier fixes the options price, exercise price for the options as well as the wholesale price for the initial procurement. Depending on the prices offered by the supplier, the HO decides on the quantities $Q$ and $q$. 


\subsection{Ordering decision by humanitarian agencies under options contract}

The profit function for HA is given by:

$$
\begin{aligned}
E\left(\pi_{H}(Q, q)\right)= & S E[X]+V E \operatorname{Max}(Q-X, 0)-P Q-c q \\
& -P_{o} E \operatorname{Min}(\operatorname{Max}(X-Q, 0), q)-P_{I} E \operatorname{Max}(X-(Q+q), 0)
\end{aligned}
$$

The first term in the profit function gives total satisfaction value derived by meeting the aid requirement of the beneficiaries. The second term shows the net salvage value of unused aid material. The third term gives the cost of buying the aid material at regular pricing. Fourth and fifth terms show the cost of purchasing option for $q$ quantities and conditional cost of exercising options respectively. The last term shows the cost of buying the aid material instantaneously after the disaster for meeting the demand over and above the maximum committed quantity by the supplier.

Taking the partial first-order condition w.r.t $Q$ and $q$ gives,

$$
\begin{aligned}
-\left(P-P_{I}\right)- & \left(P_{o}-V\right) F(Q)-\left(P_{I}-P_{O}\right) F(Q+q)=0 \\
-\left(P_{o}+c-P_{I}\right)-\left(P_{I}-P_{o}\right) F(Q+q) & =0
\end{aligned}
$$

Solving for $Q$ and $q$

$$
\begin{gathered}
Q=F^{-1}\left[\frac{P_{O}+c-P}{P_{O}-V}\right] \\
q=F^{-1}\left[\frac{P_{I}-c-P_{O}}{P_{I}-P_{O}}\right]-Q
\end{gathered}
$$

Rearranging,

$$
\frac{P_{O}+c-P}{P_{O}-V} \leq \frac{P_{I}-c-P_{O}}{P_{I}-P_{O}}
$$

The above inequality can also be expressed as

$$
c\left(P_{I}-V\right)+P_{O}(P-V) \leq P_{I}(P-V)
$$

Proposition 1 The objective function is jointly concave in $(Q, q)$, and the optimal decisions of $\mathrm{HO}$ are as follows:

1. If the inequality in Eq. (10) is satisfied, then the optimal ordering quantities are given by Eqs. (7) and (8).

2. For all other conditions, the $q=0$ and $Q=Q_{D}$

The joint concavity in $(Q, q)$ follows directly from the objective function for $\mathrm{HO}$ in Eq. (5) since the second-order conditions on $\frac{\partial^{2} E\left(\pi_{H}\right)}{\partial Q^{2}}<0$. Furthermore, the $\operatorname{Max}(X, 0)$ is an increasing function and linearity of $Q+q$ preserves the concavity since $\mathrm{HO}$ procures only a part of the total forecast during the pre-disaster phase, $F^{-1}(Q) \leq F^{-1}(Q+q)$ as given in Eq. (8). As long as the condition in Eq. (9) is met, the total forecasted requirement by the $\mathrm{HO}$ is split between pre-disaster procurement and options to buy based on the demand after the disaster. The optimal quantities for the initial and option procurement $Q$ and $q$ are well defined using the Eqs. (7) and (8) in Proposition 1 (1) respectively. However, if the condition is violated, i.e. $F^{-1}(Q)>F^{-1}(Q+q)$ is possible only when the optional purchase $q=0$. Hence, the procurement problem for $\mathrm{HO}$ becomes same as the decentralized procurement with $Q=Q_{D}$ as shown in proposition 1(2). For the second case in Proposition 1, the HO does not have any incentive to adopt options contract model and the expected profit of $\mathrm{HO}$ and supplier is the same as observed in the decentralized newsvendor problem. 


\subsubsection{Profit function of supplier}

If the supplier agrees to the staggered procurement requirement proposed by the HO, the supplier is required to identify optimal option price and exercise price under the options contract, and subsequently the optimal stocking quantity $Q_{S}$ which maximises their profit. The supplier's profit function is given by

$$
\begin{aligned}
E\left(\pi_{S}\right)= & P Q+c q+P_{O} E \operatorname{Min}(\operatorname{Max}(X-Q, 0), q)+\operatorname{VEMax}(q-\operatorname{Max}(X-Q, 0), 0) \\
& +P_{I} E \operatorname{Max}\left(X-Q_{S}, 0\right)-w Q_{S}-w_{I} E \operatorname{Max}\left(X-Q_{S}, 0\right)
\end{aligned}
$$

The first term captures the supplier revenue due to the sale of aid material under predisaster fixed order quantity. The second term shows the income from the sale of options to the $\mathrm{HO}$ for a deferred purchase and the third term gives the conditional revenue from the exercise of the options contract by the HO during the post-disaster condition. The fourth term denotes the income from salvaging the leftover aid material beyond the planning horizon. The fifth term indicates the additional revenue from the instantaneous purchase by $\mathrm{HO}$ over and above the total committed quantity by the supplier. The sixth and seventh term gives the cost of procurement of aid material under regular and instantaneous purchase, respectively.

Proposition 2 The suppliers' optimal ordering quantity would be determined as follows (All proofs are shown in the "Appendix")

$$
Q_{S}^{*}= \begin{cases}Q & \text { if } Q>F^{-1}\left[\frac{c+P_{O}-P_{I}-w+w_{I}}{P_{o}-V-P_{I}+w_{I}}\right] \\ F^{-1}\left[\frac{c+P_{O}-P_{I}-w+w_{I}}{P_{o}-V-P_{I}+w_{I}}\right] & \text { otherwise }\end{cases}
$$

Based on the orders of the HO, the supplier has to decide their production quantity. Proposition 2 indicates the conditions under which the supplier will produce according to the optimal values of the options contracts. The supplier's optimal production $Q_{S}^{*}$ is given by $F^{-1}\left[\frac{c+P_{O}-P_{I}-w+w_{I}}{P_{o}-V-P_{I}+w_{I}}\right]$. However, the actual production would not be always $Q_{S}^{*}$, as it would also depend on the order placed by the HO. If the initial fixed order $(Q)$ place by the $\mathrm{HO}$ at the beginning of the planning horizon is greater than $Q_{S}^{*}$, the supplier's production quantity would be $Q$. The supplier will produce more than $Q$ only when the $Q>F^{-1}$ $\left[\frac{c+P_{O}-P_{I}-w+w_{I}}{P_{o}-V-P_{I}+w_{I}}\right]$. Otherwise, there is no incentive for the supplier to produce more than $Q$ since the supplier is exposed to higher risk by trying to meet the commitment towards HO. If the initial order by the HO is less than $Q_{S}^{*}$, then the supplier would produce $Q_{S}^{*}$, and would offer HO to buy the option to procure extra quantities at a later time. This is in line with Proposition 1(2), where the HO does not find any incentive in ordering over and above $q$.

The combination of the option price and exercise price becomes critical to entice the HO to opt for the options contract. Also, it is in the interest of channel coordination to incentivise the HO to increase their procurement to quantity under the centralized HSC.

Proposition 3 The channel coordination can be achieved by

1. The optimal ordering quantity of the supplier $Q_{S}^{*}=Q_{C}^{*}$ and $Q_{S}^{*}>Q$.

2. The option exercise prices for quantities ordered under options contract $P_{O}=P_{I}-c$ $\left[\frac{w_{I}-V}{w-V}\right]$

3. The options prices for quantities under options contract should follow the relationship $0 \leq c<\left(P_{I}-V\right)\left[\frac{w-V}{w_{I}-V}\right]$ 
As indicated earlier, the supplier will set both the options and the exercise prices under the options contract. Here, the supplier is better off by charging a higher options price and a lower exercise price and thereby shifts the risk due to uncertainty to the HO. However, a higher option price will discourage $\mathrm{HO}$ to procure options at the beginning of the planning horizon. Hence, in proposition 3(1) if the supplier should produce $Q_{S}^{*}=Q_{C}^{*}$ (where $Q_{S}^{*}>Q$ ) the $\mathrm{HO}$ should also be motivated to procure the extra quantities over and about the initial fixed order $Q$ (since $0 \leq Q \leq Q_{c}^{*}$ ). To incentivise the supplier, the net revenue for a supplier under the options contract purchases should be higher. Since the exercise price and the option price are negatively correlated, the supplier needs to choose their combination carefully. While the option price ensures a guaranteed revenue, the exercise price provides only a conditional revenue. Hence, the supplier would be tempted to charge a higher option price. However, a higher option price would deter the $\mathrm{HO}$ to accept the offer for options contract in the first place.

In contrast, a very low option price can lead the HO to overcommit, without any obligation, which can push the risk of uncertain demand on the supplier. Proposition 3 ( 2 and 3 ) gives the conditions to identify the combination of option and exercise price, which will incentivize the supplier to match their optimal production quantity with that of the centralized supply chain. Another observation that can be made is that when the option price is zero, the exercise price becomes $P_{I}$. This indicates that without the option contract, the $\mathrm{HO}$ will be forced to procure the aid materials at the instantaneous price. This would seem more profitable to the supplier in the first instance. But in practice, this would leave both the supplier and HO worse off, since the marginal profit made by the supplier by selling at $P_{I}$ would be lower than selling the aid material at $P$ owing to the higher procurement cost of $w_{I}$.

\subsection{Channel coordination}

The pricing of the options contract helps in achieving coordination by incentivizing the supplier and HO to produce and procure up to the centralized levels, respectively. However, for the $\mathrm{HO}$, the challenge lies in identifying the split between the initial fixed order and option purchases at the beginning of the planning horizon. Since, $0 \leq Q \leq Q_{C}^{*}$,

$$
0 \leq \frac{P_{O}+c-P}{P_{O}-V} \leq \frac{w_{I}-w}{w_{I}-V}
$$

Rearranging,

$$
P-c \leq P_{O} \leq V+\left(\frac{w_{I}-V}{w-V}\right)(P-c-V)
$$

The Eq. (13) shows the range for the exercise price for the additional optimal purchase by the HO. The least value of exercise price is the difference between the initial options price and wholesale purchase price. In other words, the supplier would not sell for an amount less than the initial wholesale price under the options contract. On the other side, the upper limit for $P_{o}$ is in line with the assumption (v), where if the exercise price is less than the salvage value, the supplier would prefer to salvage the items at their end rather than honouring the contract.

Also, Proposition 3(2) gives the limit on the exercise price under the option contract, and it can be rearranged to get

$$
c\left(w_{I}-V\right)+P_{O}(w-V)=P_{I}(w-V)
$$


Similarly, the limiting condition of the inequalities in Eq. (13) takes the form of

$$
\begin{gathered}
V\left(w_{I}-w\right)=(P-c)\left(w_{I}-V\right)-P_{o}(w-V) \\
P_{o}+c=P
\end{gathered}
$$

Proposition 4 The HSC achieves coordination when the option and exercise prices under the options contract belong to the interval given by

$$
\left(c, P_{o}\right) \in\left[\left(\frac{P_{I}(w-V)-V\left(w-w_{I}\right)-P\left(w_{I}-V\right)}{2\left(w_{O}-V\right)}, V+\left(\frac{w_{I}-V}{w-V}\right)(P-c-V)\right),\left(\frac{\left(P_{I}-P\right)(w-V)}{\left(w_{I}-2 V+w\right)}, P-c\right)\right]
$$

Equation (15) and (16) shows the limiting conditions for the exercise price for the given options price under the options contract, while the relation in Eq. (14) demonstrates the condition for the exercise price. While the channel coordination can be achieved for all combination of option and exercise price, the actual number of units which can be ordered under the options contract is limited by the extra units produced by the supplier over the initial fixed order. These limits are also represented by the quantity limit line given by Eqs. (15) and (16). Hence, the actual range of prices over which the option and exercise price that would be valid is given by the intersection of the exercise price curve with the quantity limit curve. Since the channel coordination is achieved on the whole exercise price curve, the combination of option and exercise price for achieving coordination is not a unique point estimate, but a continuum. Thus, there exists a combination of option and exercise price over which the system will achieve coordination and resulting in multiple combinations of ordering quantities for the supplier and HO. The limits on the exercise price line are given in proposition 4 .

\section{Case illustration}

We demonstrate the use of the options contract in the HSC using an example of the procurement of the Therapeutic Milk cans (F100 TherapCAN $400 \mathrm{~g}$ ) for children followed by UNICEF. During emergencies, the regular packaged or processed food given to adults is usually not suitable for children. Hence, a unique form of milk (i.e., the therapeutic milk) is given to the children to either treat malnutrition or to ensure they get ample nutrition. As these products are essential relief items required for emergency response, UNICEF includes them in its Emergency Supply List. These products have a limited shelf life, and so they are not stocked at UNICEF's warehouse in Copenhagen, Denmark. Instead, they are produced on order and shipped directly from the suppliers (UNICEF 2019).

F100 TherapCAN is intended for phase 2 (nutritional rehabilitation) treatment of children with Severe Acute Malnutrition (SAM). It helps the children to transition from SAM to community-based management of acute malnutrition (CMAM), and finally help them return to their regular diet. It contains vegetable fat, carbohydrates, vitamins and minerals. Reconstituted F-100 milk provides an energy density of approximately $100 \mathrm{kcal} / 100 \mathrm{ml}$. A specified quantity of powdered therapeutic milk mixed with the specified amount of water is boiled and cooled down (to not below $70{ }^{\circ} \mathrm{C}$ ) to obtain the defined amount of liquid therapeutic diet. It is administered based on the World Health Organisation (WHO) guidelines. F-100 has an average shelf life of 18 months and needs to be stored under $30{ }^{\circ} \mathrm{C}$ (UNICEF Supply Division 2018). Each canister contains $400 \mathrm{~g}$ of F-100. Therapeutic milk diet powder is packed in cartons of 24 canisters and comes with a scoop for measurement for each serving. Each carton weighs between 13.7 and $14 \mathrm{~kg}$. 
F-100 represents about 50\% of the UNICEF annual procurement since 2011. Africa accounted for most of UNICEF's F-100 demand in 2017 (42\%), followed by the MiddleEast $(31 \%)$, and Asia (26\%). Demand from East Africa varies annually and is influenced by regular cycles of crisis and natural disasters (droughts, conflicts, and famine). Afghanistan, Angola, Democratic Republic of Congo (DRC), Ethiopia, Nigeria, and Yemen are the countries that had the highest demand for F-100 in 2017. Food and Agriculture Organization (FAO) in its global report on the food crisis (2017) reported that the spike in demand was caused due to the armed conflict in Afghanistan leading to nearly 400,000 people being internally displaced. Integrated food security phase classification (IPC) classified this crisis as an emergency to a famine-like situation. Also, the conflicts in central and eastern Africa and the Middle East combined with the effect of El Nino lead to massive food insecurity, which affected more than 5.9 Million people in DRC alone (FSIN 2017). The market for therapeutic milk accounts for about USD 41 Billion annually, and UNICEF accounts for $80 \%$ of the procurement. The major suppliers for F-100 therapeutic milk currently are Nutriset and Aspen Pharmacare. Owing to vulnerable nature of the beneficiaries requiring it, UNICEF is planning to seek a third manufacturer to ensure continuous supply availability and mitigate any risks that could disrupt therapeutic milk supply (UNICEF Supply Division 2018).

The price of therapeutic milk is heavily dependent on several factors the price of milk powder (which fluctuates significantly according to shifts in global supply and demand), availability of packaging materials, USD-EUR foreign exchange rate fluctuations, etc. The procurement price for a carton of the F-100 is obtained from the UNICEF procurement catalogue while other prices are based on our interactions with the practitioners. Prices (in USD) for modelling are set as follows: $P=60 ; P_{I}=90 ; V=10 ; w=30 ; w_{I}=40$. We consider the market to follow a demand having a normal distribution $N(100,000,25,000)$, which represents the demand for F-100 for a given planning horizon. The options contract model discussed in Sect. 3 is aimed to help the HO and the supplier to identify the optimal orders split between the initial fixed order and option purchase and the range of option and exercise prices respectively.

\section{Results}

In the centralized HSC, the optimal procurement quantity $\left(Q_{C}^{*}\right)$ for the $\mathrm{HO}$ is 89232 units for the planning horizon. However, with the options contract, the total aid material procurement is split between the initial fixed order and the option order. As discussed in Proposition 4, there exists a range of options and exercise price combinations meeting the criteria given in Proposition 3. Based on Proposition 4, the intersection points $\left(c_{1}, P_{O 1}\right)$ and $\left(c_{2}, P_{O 2}\right)$ representing the upper and lower limits for this combination is found as $(1.67,87.5)$ and $(12,72)$ respectively. Hence, for every combination of options and exercise price, there exists a combination of fixed initial order and options price. This is straight forward since both $Q$ and $q$ are dependent on the options and exercise price. Hence, for a given combination of options and exercise price, the results of Proposition 2 can be used to calculate both the initial fixed order and the quantity under options contract. The decision regarding the combination of $\left(c, P_{o}\right)$ and the corresponding ordering quantities by $\mathrm{HO}(Q, q)$ under the options contract is summarized in Table 1. It can be observed that under the limiting conditions, for every possible combination of options and exercise price set by the supplier there exists a corresponding quantity of initial order and order under options contract that can be placed by the HO such that $Q+q=Q_{C}^{*}$. 
Table 1 Order quantities under various combinations of option and exercise prices

\begin{tabular}{lllllrl}
\hline$C$ & $P_{o}$ & $C+P_{o}$ & \multicolumn{1}{l}{$Q s$} & $Q$ & $Q$ & $Q+q$ \\
\hline 1.67 & 87.50 & 89.17 & 89,232 & 89,226 & 6 & 89,232 \\
3 & 85.50 & 88.50 & 89,232 & 86,747 & 2485 & 89,232 \\
4 & 84.00 & 88.00 & 89,232 & 84,700 & 4532 & 89,232 \\
5 & 82.50 & 87.50 & 89,232 & 82,453 & 6779 & 89,232 \\
6 & 81.00 & 87.00 & 89,232 & 79,949 & 9283 & 89,232 \\
7 & 79.50 & 86.50 & 89,232 & 77,102 & 12,130 & 89,232 \\
8 & 78.00 & 86.00 & 89,232 & 73,772 & 15,460 & 89,232 \\
9 & 76.50 & 85.50 & 89,232 & 69,703 & 19,528 & 89,232 \\
10 & 75.00 & 85.00 & 89,232 & 64,348 & 24,884 & 89,232 \\
11 & 73.50 & 84.50 & 89,232 & 56,049 & 33,183 & 89,232 \\
11.98 & 72.02 & 84.01 & 89,232 & 16,234 & 72,998 & 89,232 \\
\hline
\end{tabular}

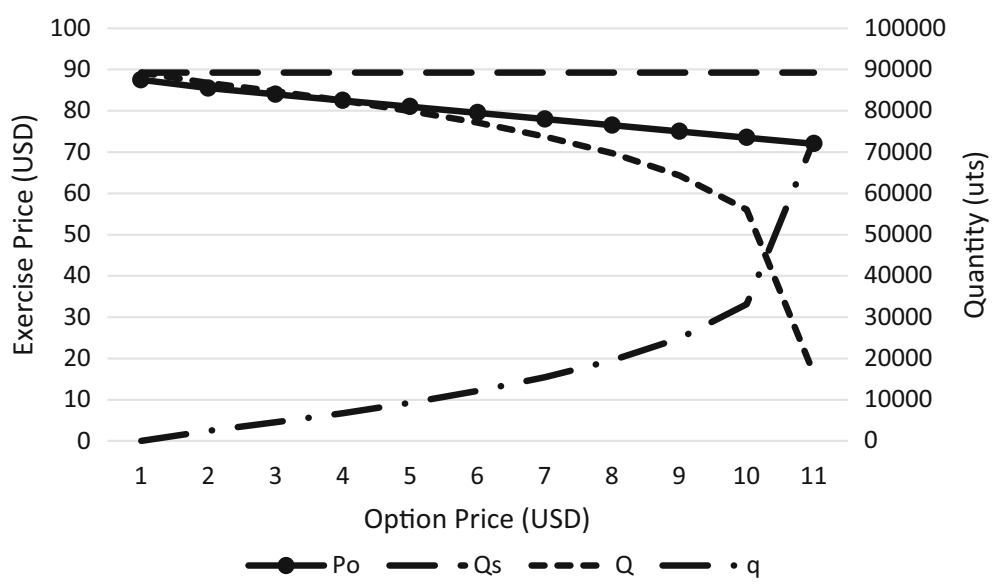

Fig. 1 Variation of options price with respect to the exercise price

Within the optimal range, the supplier's production quantity is constant and equal to the centralized production quantity. The entire production is split between the two parts of the order placed by the HO. Figure 1 shows the variation of $Q, q$, and $Q_{s}$ with respect to the options price and exercise price. The points on the line segment between $\left(c_{1}, P_{O 1}\right)$ and $\left(c_{2}, P_{O 2}\right)$ represent the range within which the $\mathrm{HO}$ and supplier can negotiate for options and exercise prices. Table 1 indicates a subset of possible combinations of initial order and options order. The split between the initial order quantity and order quantity under the options contract is a matter of internal policy decision. However, the results suggest that $\mathrm{HO}$ can still choose from a wide range of choices while still achieving systemic coordination since the joint order matches the order under a centralized model.

Figure 1 shows that as long as the options price and exercise price are set between the ranges given by Proposition 4, the optimal production by the supplier coincides with the optimal procurement units in a centralized HSC. Furthermore, the optimal orders placed by the HO under the initial fixed order and the options contract adds up to the optimal orders under the centralized quantity. It indicates that the options contracts can achieve coordination when used along with the fixed order quantities. It is also true since if the initial order quantity 
by the $\mathrm{HO}$ is more than the optimal ordering quantity in the centralized HSC, the supplier restricts the production quantity as suggested in the Proposition 2 . This is because the total cost of the aid material while choosing the options contract is almost as high as the price under the instantaneous purchase. Hence, the $\mathrm{HO}$ would be discouraged to go for the options contract and would instead buy extra quantities upfront at a lower wholesale price and wait for the actual realization of the demand. Also, within the feasible range, the range of options price and exercise price are inversely related. This coincides with the option pricing theory that higher exercise price requests lower option price.

\section{Discussion and implications}

The effectiveness of the post-disaster response by HO, such as providing relief and aid material to the affected communities after a sudden onset of disaster, often relies on the supply chain capabilities of these agencies. Kovács and Tatham (2009) stressed on the need for the HSC to develop capabilities for making a rapid switch from a lean preparedness stage to an agile response stage. HOs also have to manage their donor expectations. For instance, if a $\mathrm{HO}$ expects an increase in total contributions, then usually the donors expect an option for earmarking their donations for specific purposes. However, earmarking creates constraints in resource allocation that negatively affect HO's operational performance (Aflaki and PedrazaMartinez 2016). This usually affects investment in mechanisms such as pre-establishing adequate capacity through procurement of aid material which helps in rapid switching from lean to agile, while coordination between stakeholders during the response phase (Salmerón and Apte 2010; McLachlin and Larson 2011).

Similarly, the effective procurement of aid material is an integral part of the HO operations. Thus, HOs often search for opportunities to optimize their procurement processes through multiple mechanisms. One such frequently used mechanism is the use of an options contract for the aid material procurement. The main contribution of this study is the formalization of the procurement practices in HSC drawing from both theoretical and practical backgrounds.

\subsection{Research implications}

Liang et al. (2012) and Wang and Chen (2015) have considered the options contract as a potential mechanism for aid procurement while addressing the demand uncertainty. On the other hand, Toyasaki et al. (2017) explored the condition under which horizontal coordination can be achieved under joint procurement. Similarly, other studies (Balcik and Ak 2014; Torabi et al. 2018; Nikkhoo et al. 2018) have also tried to answer these questions using options and quantity flexibility contracts broadly. However, in practice, HOs usually does not choose between pre-purchasing or deferred purchasing, but use a combination of both to meet the forecasted demand of aid material. In this research, we explored the use of options contract in conjunction with the regular procurement and not separately, making this study closely resemble the practices followed by the HOs. From a theoretical perspective, we identified that the options contract could be used along with the regular procurement in the pre-disaster stage and thereby achieve coordination between the suppliers and HO. Furthermore, we also explained the conditions under which the HSC can achieve coordination.

The $\mathrm{HO}$ and the suppliers are two separate entities with their own distinct demand patterns. Hence, getting them to agree on a common demand distribution is difficult to achieve in practice. In our results, the optimal decision parameters are independent of each others choice 
of demand parameters. The optimal order quantity for the HO is independent of the demand distribution followed by the supplier, and it allows the HO to use demand distribution that best suits their demand patterns. As the optimum options price can take a range of values instead of point estimates, the HO can also vary their orders between the fixed and options procurement depending upon the price offered by the supplier and still achieve system-wide optimality. Therefore, the options contract provides flexibility on two fronts while enabling coordination between these two parties in the HSC. First, it allows the HO to purchase over and above the initial order at a lower price than available at the spot market. Second, even within the options contract, the $\mathrm{HO}$ can choose from a range of combinations between fixed order and options order. In addition, the HO can also identify whether the options prices offered by the supplier are suitable for them and hence could choose to accept or reject the rates provided by the supplier and negotiate for a better deal.

\subsection{Practical and policy implications}

Ascertaining the optimal prices and the order quantities split between the fixed and conditional orders has been pursued in an ad-hoc manner by the HO. While previous studies have looked into these, the optimal values for the decision parameters were point estimates. In practice, however, these point estimates are not much of help since the actual decision is based on a multitude of factors such as existing market price, type of disasters, donations received, advocacy programs, leftover stocks, etc. Currently, the ordering policies and the price negotiations between the supplier and HO do not take any measures for system optimality although they are subject to a tight budget constraint. This is also a significant reason why the decision regarding the pricing and quantity procured is often based on relationships and negotiations. In this study, we do not offer a point solution but a range for the decision parameters for achieving system optimality. Under the proposed options contract, HO and supplier can negotiate and arrive at system-wide optimal parameters and look beyond behavioural attributes while making procurement decisions. This study shows that the proposed options contract mechanism closely represents the practice in terms of the pricing and ordering decisions followed by the two parties in the HSC.

The decision about the type of contract to be used in an HSC is generally a complex one. The formulation of a contract strategy is receiving adequate attention in the literature. But it is not a well-structured process as complex interrelationships exist between the HO and suppliers. These relationships make it difficult to develop an algorithmic procedure for selecting a contract type. This study took into account the complexities involved in the procurement process of the $\mathrm{HO}$ and thereby developed a model based on the options contract as a part of the procurement strategy. While the model identifies the nature of pricing, it leaves the final decision on quantity and the prices of the contract to the procurement officer in the HO.

Our research also provides insights into the pricing policies to be adopted by the supplier as well. The main challenge faced by the supplier while pricing the options contract is to identify the combination of the initial option price (guaranteed income) versus exercise price (conditional income). Our model indicates that the options and exercise price are valid over a range and are not merely a point estimates. This range for the prices that the supplier can offer makes the option contract easy to implement. The supplier can duly suggest their best combination of the options and exercise price for the given combination of the fixed and options order quantity placed by the HO making it very practical unlike the point estimates of optimal values. Although our model did not consider the risk propensities of the two entities 
explicitly, the continuum of optimal pricing implicitly allows the parties to select the option prices depending upon the risk appetite and still achieve system optimality.

\subsection{Limitations and future scope}

While we have used a real-time example to illustrate the applicability of the proposed model, it would be beneficial to test the use of the options contract using empirical data to gain further insights into the real-world application. Also, we have not considered the lead time for the ordering process. Similarly, we have not included other parameters such as capacity constraints or minimum order commitments in our model, which might affect the decision making for the $\mathrm{HO}$ and supplier while fixing the options price and order quantities.

Our study could be extended in several ways. One possibility could be when the HO in the wake of the disaster will compare the prices in the spot market as well as the price for exercising the option contract. This possibility arises when the HO orders from supplier first and then trades in the spot market once demand and spot price uncertainty are resolved in the post-disaster scenario. This approach would undoubtedly make the ordering decision from the long-term contracted supplier more critical (because ordering from the spot market becomes easier as demand is no longer uncertain at the time of trading in the spot market). Furthermore, the model could be extended by considering the transportation cost of the aid material to the disaster site. Considering these two scenarios, the combination of the spot market price and transportation cost to the affected area will provide further insights into the decision making process in a post-disaster situation.

Another extension to our model would be to consider a portfolio of the products, where each product has various levels of urgency during the post-disaster operations. For instance, aid material such as vaccines may have a limited shelf life and also a long manufacturing lead time in comparison to that of procuring off the shelf products such as biscuits, diapers, etc. Under these conditions, the applicability of the model have to be explored further.

\section{Conclusion}

In this study, we explored the use of options contract to manage the pre-disaster procurement of aid material. While previous studies looked at the options contract as a standalone mechanism for procurement, we investigated how the options contract can be utilized in association with other procurement mechanisms. Our results show that the $\mathrm{HO}$ can use the options contract along with both regular procurement and spot market procurement. The proposed options contract is an efficient tool to achieve inter-organizational coordination in HSC by ensuring that the supplier's optimal production quantity and the combined optimal procurement by the HO match the optimal ordering quantity under centralised HSC. This makes our study relevant for the practice where the $\mathrm{HO}$ would prefer to use multiple procurement methodologies rather than sticking to any one of the methods.

Furthermore, we also identify the decision parameters, i.e. the option and exercise price combination for the supplier and the corresponding fixed and option procurement quantity for the HO, which helps achieve coordination. From a practical perspective, the results help the HOs to address the significant challenges faced during the procurement of the aid material, i.e. balancing efficiency and effectiveness of the humanitarian operations through the flexibility in aid material procurement. Furthermore, since the optimal decision parameters are not the point estimates but a continuum, prices offered by the supplier and corresponding quantities 
to ordered by the $\mathrm{HO}$ allows decentralized planning by two parties making it more conducive for practical implementation. Also, the $\mathrm{HO}$ is not required to choose between the fixed order or options contract and can still use their portfolio approach to the aid procurement. Our model suggests actionable strategies that can be transferred to practice while catering to the decision making needs of both the supplier and HO individually and yet ensure system optimality.

Open Access This article is licensed under a Creative Commons Attribution 4.0 International License, which permits use, sharing, adaptation, distribution and reproduction in any medium or format, as long as you give appropriate credit to the original author(s) and the source, provide a link to the Creative Commons licence, and indicate if changes were made. The images or other third party material in this article are included in the article's Creative Commons licence, unless indicated otherwise in a credit line to the material. If material is not included in the article's Creative Commons licence and your intended use is not permitted by statutory regulation or exceeds the permitted use, you will need to obtain permission directly from the copyright holder. To view a copy of this licence, visit http://creativecommons.org/licenses/by/4.0/.

\section{Appendix}

Proof of proposition 2 The profit function for a supplier can be written as,

$$
\begin{array}{r}
\operatorname{Max} E\left(\pi_{S}\right) \\
\text { s.t.h }\left(Q_{s}\right)=Q_{s}-Q \geq 0
\end{array}
$$

Applying Lagrangian Expansion,

$$
\left\{\begin{array}{c}
E\left(\pi_{S}^{\prime}\right)+\lambda h^{\prime}\left(Q_{s}\right)=0 \\
\lambda\left(Q_{s}-Q\right)=0
\end{array}\right.
$$

for $\lambda=0$,

$$
\begin{gathered}
E\left(\pi_{S}^{\prime}\right)=\left(c+P_{O}-P_{I}-w+w_{I}\right)-\left(P_{o}-V-P_{I}+w_{I}\right) F\left(Q_{S}\right)=0 \\
Q_{S}^{*}=F^{-1}\left[\frac{c+P_{O}-P_{I}-w+w_{I}}{P_{o}-V-P_{I}+w_{I}}\right]
\end{gathered}
$$

for $\lambda \neq 0 \lambda=\left(P_{o}-V-P_{I}+w_{I}\right) F\left(Q_{s}\right)-\left(c+P_{O}-P_{I}-w+w_{I}\right)>0$ and equivalently, $Q_{s}=Q$.

On the similar lines of argument,

$$
Q>F^{-1}\left[\frac{c+P_{O}-P_{I}-w+w_{I}}{P_{o}-V-P_{I}+w_{I}}\right]
$$

also gives $Q_{s}=Q$.

Proof of proposition 3 The coordination between supplier and HO can be achieved when $Q_{S}^{*}=Q_{C}^{*}$. Since the function $F(\cdot)$ is monotonically increasing,

$$
\frac{c+P_{O}-P_{I}-w+w_{I}}{P_{o}-V-P_{I}+w_{I}}=\frac{w_{I}-w}{w_{I}-V}
$$

On rearrangement, the optimal values of the option price and exercise price can be obtained from,

$$
\begin{gathered}
\left(c+P_{O}-P_{I}-w+w_{I}\right)\left(w_{I}-V\right)=\left(P_{o}-V-P_{I}+w_{I}\right)\left(w_{I}-w\right) \\
P_{O}=P_{I}-c\left[\frac{w_{I}-V}{w-V}\right]
\end{gathered}
$$


Furthermore, while satisfying the assumption (v), $P_{O}>V$, the option price can take any value between,

$$
0 \leq c<\left(P_{I}-V\right)\left[\frac{w-V}{w_{I}-V}\right]
$$

From the preceding discussion, we arrive at the second proposition.

Proof of proposition 4 The boundary condition for the channel to be coordinated on the line

$$
c\left(w_{I}-V\right)+P_{O}(w-V)=P_{I}(w-V)
$$

is given by points $\left(c_{1}, P_{O 1}\right)=\left(\frac{P_{I}(w-V)-V\left(w-w_{I}\right)-P\left(w_{I}-V\right)}{2\left(w_{I}-V\right)}, V+\left(\frac{w_{I}-V}{w-V}\right)(P-c-V)\right)$ and $\left(c_{2}, P_{O 2}\right)=\left(\frac{\left(P_{I}-P\right)(w-V)}{\left(w_{I}-2 V+w\right)}, P-c\right)$, where every point on the line segment will have HO's order quantity is decreasing in $c$.

$$
\begin{gathered}
c\left(w_{I}-V\right)+P_{O}(w-V)=P_{I}(w-V) \\
\frac{w_{I}-V}{w-V}=\frac{P_{O}-P_{I}}{c} \\
\frac{w-w_{I}}{w_{I}-V}=\frac{c+P_{O}-P_{I}}{P_{O}-P_{I}} \\
Q_{C}^{*}=F^{-1}\left[\frac{w_{I}-w}{w_{I}-V}\right]=F^{-1}\left[\frac{P_{I}-c-P_{o}}{P_{I}-P_{o}}\right]=Q+q
\end{gathered}
$$

\section{References}

Aflaki, A., \& Pedraza-Martinez, A. J. (2016). Humanitarian funding in a multi-donor market with donation uncertainty. Production and Operations Management, 25(7), 1274-1291.

Al Qundus, J., Dabbour, K., Gupta, S., Meissonier, R., \& Paschke, A. (2020). Wireless sensor network for AI-based flood disaster detection. Annals of Operations Research. https://doi.org/10.1007/s10479-02003754-X.

Altay, N., \& Labonte, M. (2014). Challenges in humanitarian information management and exchange: Evidence from Haiti. Disasters, 38(s1), S50-S72.

Balcik, B., \& Ak, D. (2014). Supplier selection for framework agreements in humanitarian relief. Production and Operations Management, 23(6), 1028-1041.

Balcik, B., Beamon, B. M., Krejci, C. C., Muramatsu, K. M., \& Ramirez, M. (2010). Coordination in humanitarian relief chains: Practices, challenges and opportunities. International Journal of Production Economics, 126(1), 22-34.

Barnes-Schuster, D., Bassok, Y., \& Anupindi, R. (2002). Coordination and flexibility in supply contracts with options. Manufacturing \& Service Operations Management, 4, 171-207.

Behl, A., \& Dutta, P. (2019). Humanitarian supply chain management: A thematic literature review and future directions of research. Annals of Operations Research, 283(1), 1001-1044.

Bemley, J. L., Davis, L. B., \& Brock, L. G., III. (2013). Pre-positioning commodities to repair maritime navigational aids. Journal of Humanitarian Logistics and Supply Chain Management, 3(1), 65-89.

Ben-Tal, A., Golany, B., Nemirovski, A., \& Vial, J. P. (2005). Retailer-supplier flexible commitments contracts: A robust optimization approach. Manufacturing \& Service Operations Management, 7, 248-271.

Black, F., \& Scholes, M. (1973). The pricing of options and corporate liabilities. Journal of Political Economy, $81,637-654$

Cachon, G. P. (2003). Supply chain coordination with contracts. Handbooks in operations research and management science, 11, 227-339.

Chen, X., \& Shen, Z. J. (2012). An analysis of a supply chain with options contracts and service requirements. IIE Transactions, 44(10), 805-819. 
Chen, X., Hao, G., \& Li, L. (2014). Channel coordination with a loss-averse retailer and option contracts. International Journal of Production Economics, 150, 52-57.

Chen, J., Liang, L., \& Yao, D. Q. (2017). Pre-positioning of relief inventories for non-profit organizations: A newsvendor approach. Annals of Operations Research, 259(1-2), 35-63.

Day, J. M., Melnyk, S. A., Larson, P. D., Davis, E. W., \& Whybark, D. C. (2012). Humanitarian and disaster relief supply chains: A matter of life and death. Journal of Supply Chain Management, 48(2), 21-36.

Dubey, R., Altay, N., \& Blome, C. (2019a). Swift trust and commitment: The missing links for humanitarian supply chain coordination? Annals of Operations Research, 283(1), 159-177.

Dubey, R., Gunasekaran, A., Childe, S. J., Roubaud, D., Wamba, S. F., Giannakis, M., et al. (2019b). Big data analytics and organizational culture as complements to swift trust and collaborative performance in the humanitarian supply chain. International Journal of Production Economics, 210, 120-136.

Dubey, R., Luo, Z., Gunasekaran, A., Akter, S., Hazen, B. T., \& Douglas, M. A. (2018). Big data and predictive analytics in humanitarian supply chains: Enabling visibility and coordination in the presence of swift trust. The International Journal of Logistics Management, 29(2), 485-512.

Edrissi, A., Poorzahedy, H., Nassiri, H., \& Nourinejad, M. (2013). A multi-agent optimization formulation of earthquake disaster prevention and management. European Journal of Operational Research, 229(1), 261-275.

Eppen, G. D., \& Iyer, A. V. (1997). Backup agreements in fashion buying-The value of upstream flexibility. Management Science, 43(11), 1469-1484.

Eriksson, K. (2019). An option mechanism to coordinate a dyadic supply chain bilaterally in a multi-period setting. Omega, 88, 196-209.

Ertem, M., \& Buyurgan, N. (2011). An auction-based framework for resource allocation in disaster relief. Journal of Humanitarian Logistics and Supply Chain Management, 1(2), 170-188.

Ertem, M., Buyurgan, N., \& Rossetti, M. (2010). Multiple-buyer procurement auctions framework for humanitarian supply chain management. International Journal of Physical Distribution and Logistics Management, 40(3), 202-227.

Fathalikhani, S., Hafezalkotob, A., \& Soltani, R. (2018). Cooperation and coopetition among humanitarian organizations: A game theory approach. Kybernetes, 47(8), 1642-1663.

Fathalikhani, S., Hafezalkotob, A., \& Soltani, R. (2020). Government intervention on cooperation, competition, and coopetition of humanitarian supply chains. Socio-Economic Planning Sciences, 69, 100715.

Fawcett, A. M., \& Fawcett, S. E. (2013). Benchmarking the state of humanitarian aid and disaster relief: A systems design perspective and research agenda. Benchmarking: An International Journal, 20(5), 661-692.

Food Security Information Network (2017). Global report on food crises. Retrieved June 1, 2020, from http:// www.fao.org/3/a-br323e.pdf.

Gulati, R., Wohlgezogen, F., \& Zhelyazkov, P. (2012). The two facets of collaboration: Cooperation and coordination in strategic alliances. Academy of Management Annals, 6(1), 531-583.

Heaslip, G., Sharif, A. M., \& Althonayan, A. (2012). Employing a systems-based perspective to the identification of inter-relationships within humanitarian logistics. International Journal of Production Economics, 139(2), 377-392.

Holguín-Veras, J., Pérez, N., Jaller, M., Van Wassenhove, L. N., \& Aros-Vera, F. (2013). On the appropriate objective function for post-disaster humanitarian logistics models. Journal of Operations Management, 31(5), 262-280.

Hu, Z., Tian, J., \& Feng, G. (2019). A relief supplies purchasing model based on a put option contract. Computers \& Industrial Engineering, 127, 253-262.

Inderfurth, K., \& Clemens, J. (2014). Supply chain coordination by risk sharing contracts under random production yield and deterministic demand. OR Spectrum, 36(2), 525-556.

Jabbour, C. J. C., Sobreiro, V. A., de Sousa Jabbour, A. B. L., de Souza Campos, L. M., Mariano, E. B., \& Renwick, D. W. S. (2019). An analysis of the literature on humanitarian logistics and supply chain management: paving the way for future studies. Annals of Operations Research, 283(1), 289-307.

Jahre, M., \& Fabbe-Costes, N. (2015). How standards and modularity can improve humanitarian supply chain responsiveness: The case of emergency response units. Journal of Humanitarian Logistics and Supply Chain Management, 5(3), 348-386.

Jensen, L. M., \& Hertz, S. (2016). The coordination roles of relief organisations in humanitarian logistics. International Journal of Logistics Research and Applications, 19(5), 465-485.

Kabra, G., \& Ramesh, A. (2015). Analyzing drivers and barriers of coordination in humanitarian supply chain management under fuzzy environment. Benchmarking An International Journal, 22(4), 559-587.

Kovács, G., \& Tatham, P. (2009). Responding to disruptions in the supply network-from dormant to action. Journal of Business Logistics, 30(2), 215-229. 
Lamenza, A. A. D. S., Fontainha, T. C., \& Leiras, A. (2019). Purchasing strategies for relief items in humanitarian operations. Journal of Humanitarian Logistics and Supply Chain Management, 9(2), 151-171.

Li, Q., Niu, B., \& Chu, L. K. (2016). Forward sourcing or spot trading? Optimal commodity procurement policy with demand uncertainty risk and forecast update. IEEE Systems Journal, 11(3), 1526-1536.

Liang, L., Wang, X., \& Gao, J. (2012). An option contract pricing model of relief material supply chain. Omega, 40(5), 594-600.

Liu, Y., Tian, J., Feng, G., \& Hu, Z. (2019). A relief supplies purchasing model via option contracts. Computers \& Industrial Engineering, 137, 106009.

Lodree, E. J., Jr. (2011). Pre-storm emergency supplies inventory planning. Journal of Humanitarian Logistics and Supply Chain Management, 1(1), 50-77.

Loree, N., \& Aros-Vera, F. (2018). Points of distribution location and inventory management model for PostDisaster Humanitarian Logistics. Transportation Research Part E: Logistics and Transportation Review, 116, 1-24.

Loynes, C., Ouenniche, J., \& De Smedt, J. (2020). The detection and location estimation of disasters using twitter and the identification of non-governmental organisations using crowdsourcing. Annals of Operations Research. https://doi.org/10.1007/s10479-020-03684-8.

Makepeace, D., Tatham, P., \& Wu, Y. (2017). Internal integration in humanitarian supply chain management. Journal of Humanitarian Logistics and Supply Chain Management, 7(1), 26-56.

McGinnis, M. D. (2000). Policy substitutability in complex humanitarian emergencies. Journal of Conflict Resolution, 44(1), 62-89.

McLachlin, R., \& Larson, P. D. (2011). Building humanitarian supply chain relationships: lessons from leading practitioners. Journal of Humanitarian Logistics and Supply Chain Management, 1(1), 32-49.

Morales, M., \& Sandlin, D. E. (2015). Managing airborne relief during international disasters. Journal of Humanitarian Logistics and Supply Chain Management, 5(1), 12-34.

Moshtari, M. (2016). Inter-organizational fit, relationship management capability, and collaborative performance within a humanitarian setting. Production and Operations Management, 25(9), 1542-1557.

Muggy, L., \& Stamm, J. L. H. (2020). Decentralized beneficiary behavior in humanitarian supply chains: Models, performance bounds, and coordination mechanisms. Annals of Operations Research, 284(1), 333-365.

Nagendra, N. P., Narayanamurthy, G., \& Moser, R. (2020). Management of humanitarian relief operations using satellite big data analytics: The case of Kerala floods. Annals of Operations Research. https://doi. org/10.1007/s10479-020-03593-w.

Nikkhoo, F., Bozorgi-Amiri, A., \& Heydari, J. (2018). Coordination of relief items procurement in humanitarian logistic based on quantity flexibility contract. International Journal of Disaster Risk Reduction, 31, $331-340$.

Nosoohi, I., \& Nookabadi, A. S. (2016). Outsource planning through option contracts with demand and cost uncertainty. European Journal of Operational Research, 250, 131-142.

Pedraza Martinez, A. J., Stapleton, O., \& van Wassenhove, L. N. (2011). Field vehicle fleet management in humanitarian operations: A case-based approach. Journal of Operations Management, 29(5), 404-421.

Russell, T. E. (2005). The humanitarian relief supply chain: analysis of the 2004 South East Asia earthquake and tsunami (Doctoral dissertation, Massachusetts Institute of Technology).

Salmerón, J., \& Apte, A. (2010). Stochastic optimization for natural disaster asset prepositioning. Production and Operations Management, 19(5), 561-574.

Santarelli, G., Abidi, H., Klumpp, M., \& Regattieri, A. (2015). Humanitarian supply chains and performance measurement schemes in practice. International Journal of Productivity and Performance Management, 64(6), 784-810.

Scholten, K., de Blok, C., \& Haar, R. J. (2018). How flexibility accommodates demand variability in a service chain: insights from exploratory interviews in the refugee supply chain. In: The Palgrave Handbook of Humanitarian Logistics and Supply Chain Management (pp. 359-393). Palgrave Macmillan, London.

Seaman, J. (1999). Malnutrition in emergencies: How can we do better and where do the responsibilities lie? Disasters, 23(4), 306-315.

Serel, D. A., Dada, M., \& Moskowitz, H. (2001). Sourcing decisions with capacity reservation contracts. European Journal of Operational Research, 131(3), 635-648.

Shamsi, G. N., Ali Torabi, S., \& Shakouri, G. H. (2018). An option contract for vaccine procurement using the SIR epidemic model. European Journal of Operational Research, 267(3), 1122-1140.

Sheppard, A., Tatham, P., Fisher, R., \& Gapp, R. (2013). Humanitarian logistics: Enhancing the engagement of local populations. Journal of Humanitarian Logistics and Supply Chain Management, 3(1), 22-36.

Shi, W., \& Feng, T. (2016). Examining supply contracts under cost and demand uncertainties from supplier's perspective: A real options approach. International Journal of Production Research, 54(1), 83-97. 
Spinler, S., \& Huchzermeier, A. (2006). The valuation of options on capacity with cost and demand uncertainty. European Journal of Operational Research, 171(3), 915-934.

Stephenson, M., Jr. (2005). Making humanitarian relief networks more effective: Operational coordination, trust and sense making. Disasters, 29(4), 337-350.

Stephenson, M, Jr., \& Schnitzer, M. H. (2006). Interorganization al trust, boundary spanning, and humanitarian relief coordination. Non profit management and leadership, 17(2), 211-233.

Tatham, P., \& Kovács, G. (2010). The application of "swift trust" to humanitarian logistics. International Journal of Production Economics, 126(1), 35-45.

Torabi, S. A., Shokr, I., Tofighi, S., \& Heydari, J. (2018). Integrated relief pre-positioning and procurement planning in humanitarian supply chains. Transportation Research Part E: Logistics and Transportation Review, 113, 123-146.

Toyasaki, F., Arikan, E., Silbermayr, L., \& Falagara Sigala, I. (2017). Disaster relief inventory management: Horizontal cooperation between humanitarian organizations. Production and Operations Management, 26(6), 1221-1237.

Tsay, A. A. (1999). The quantity flexibility contract and supplier-customer incentives. Management Science, 45(10), 1339-1358.

Turkeš, R., Cuervo, D. P., \& Sörensen, K. (2019). Pre-positioning of emergency supplies: Does putting a price on human life help to save lives? Annals of Operations Research, 283(1), 865-895.

UNICEF, (2018). Annual Supply Report 2018. Retrieved Dec 12, 2019, from https://www.unicef.org/supply/ files/Unicef-Supply-Annual-Report-2018.pdf.

UNICEF, List of Approved Emergency Items: Emergency Supply List, UNICEF, Copenhagen, September 2019. Retrieved June 6, 2020, from https:/www.unicef.org/supply/media/1196/file/ESL-Nov2019.pdf.

Van der Laan, E., van Dalen, J., Rohrmoser, M., \& Simpson, R. (2016). Demand forecasting and order planning for humanitarian logistics: An empirical assessment. Journal of Operations Management, 45, 114-122.

Van Wassenhove, L. N. (2006). Humanitarian aid logistics: Supply chain management in high gear. Journal of the Operational Research Society, 57(5), 475-489.

Wagner, S. M., \& Thakur-Weigold, B. (2018). Supporting collaboration in humanitarian supply chains-insights from a design science project. Production Planning \& Control, 29(14), 1130-1144.

Wamba, S. F. (2020). Humanitarian supply chain: A bibliometric analysis and future research directions. Annals of Operations Research. https://doi.org/10.1007/s10479-020-03594-9.

Wang, C., \& Chen, X. (2015). Optimal ordering policy for a price-setting newsvendor with option contracts under demand uncertainty. International Journal of Production Research, 53(20), 6279-6293.

Wang, X., Fan, Y., Liang, L., De Vries, H., \& Van Wassenhove, L. N. (2019). Augmenting fixed framework agreements in humanitarian logistics with a bonus contract. Production and Operations Management, 28(8), 1921-1938.

Wang, X., Li, F., Liang, L., Huang, Z., \& Ashley, A. (2015). Pre-purchasing with option contract and coordination in a relief supply chain. International Journal of Production Economics, 167, 170-176.

Xiao, G., Yang, N., \& Zhang, R. (2015). Dynamic pricing and inventory management under fluctuating procurement costs. Manufacturing \& Service Operations Management, 17(3), 321-334.

Xu, J., Gürbüz, M. C., Feng, Y., \& Chen, S. (2020). Optimal spot trading integrated with quantity flexibility contracts. Production and Operations Management. https://doi.org/10.1111/poms.13180.

Yao, X., Huang, R., Song, M., \& Mishra, N. (2018). Pre-positioning inventory and service outsourcing of relief material supply chain. International Journal of Production Research, 56(21), 6859-6871.

Yi, W., \& Özdamar, L. (2007). A dynamic logistics coordination model for evacuation and support in disaster response activities. European Journal of Operational Research, 179(3), 1177-1193.

Zhao, Y., Wang, S., Cheng, T. E., Yang, X., \& Huang, Z. (2010). Coordination of supply chains by option contracts: A cooperative game theory approach. European Journal of Operational Research, 207(2), $668-675$.

Publisher's Note Springer Nature remains neutral with regard to jurisdictional claims in published maps and institutional affiliations.

\section{Affiliations}

\section{Lijo John ${ }^{1} \cdot$ Anand Gurumurthy ${ }^{2}$ (D) Arqum Mateen ${ }^{2}$. Gopalakrishnan Narayanamurthy ${ }^{3}$ D}


Gopalakrishnan Narayanamurthy

G.Narayanamurthy@liverpool.ac.uk

Lijo John

lijo.john@spjimr.org

Anand Gurumurthy

anandg@iimk.ac.in

Arqum Mateen

arqumm@iimk.ac.in

1 Operations and Supply Chain Management Area, S P Jain Institute of Management Research (SPJIMR) Bhavan's Campus, Munshi Nagar, Dadabhai Road, Andheri West, Mumbai 400058, India

2 Quantitative Methods and Operations Management (QM and OM) Area, Indian Institute of Management Kozhikode (IIMK), IIMK Campus P.O., Kunnamangalam, Kozhikode 673570, Kerala, India

3 Department of Operations and Supply Chain Management, University of Liverpool Management School, Chatham Street, Liverpool L69 7ZH, UK 